\title{
El coraje en el gobierno de las pasiones: notas sobre Platón y los cínicos antiguos \\ Courage in the Government of Passions: Notes on Plato and the Ancient Cynics
}

\author{
INMACULADA Hoyos SÁNCHEZ \\ Universidad de Granada \\ ihoyos@ugr.es
}

Recibido: 07/08/2019 - Aceptado: 17/02/2020
DOI https://doi.org/10.20318/fons.2019.4915

\begin{abstract}
Resumen
El propósito de este estudio es reflexionar acerca de las distintas concepciones que del coraje y sus funciones han tenido algunas escuelas de la Antigüedad en el marco de una política entendida como gobierno de las pasiones. En este artículo se compara la perspectiva de Platón con el enfoque del cinismo. En la primera sección, se analiza el papel de la educación musical en la República. Dicha educación, según Platón, fomenta el verdadero coraje entre los guardianes y evita su brutalidad. En la segunda sección, se consideran las diferencias entre el platonismo y el cinismo. Éste último presentó una nueva manera de entender el coraje, como un modo de vida que no requiere ningún tipo de pedagogía musical, sino un entrenamiento constante para superar la vergüenza. Además, el coraje, para el cínico, no es la virtud específica de una clase del estado, la de los guardianes, sino que es un modo de vida que cualquier individuo puede adoptar aplicando una terapia correctora.
\end{abstract}

Palabras clave: Platón, cinismo, coraje, música, vergüenza

\begin{abstract}
The following paper compares Plato's proposal with the approach of cynicism concerning the virtue of courage. The first section studies role of musical education in the Republic, which contributes to foster real courage among the guardians and avoids brutality. The second section exposes the differences between Platonism and Cynicism. The latter presented a new way of understanding courage, as a way of life, which does not require a musical pedagogy, but training in overcoming shame. Courage, according to the Cynics, is not the specific virtue of a class but is a way of life that any individual can adopt.
\end{abstract}

Key words: Plato, Cynicism, courage, music, shame

\section{Una opinión indeleble: Platón ${ }^{1}$}

De todos es conocida la imposibilidad de definir en sentido estricto el coraje (andreía) que Platón encontraba en el Laques. P. Tillich en las conferencias sobre el

\footnotetext{
${ }_{1}$ Agradezco a A. Vallejo Campos el haber señalado que la expresión tintura indeleble (VALLEJO CAMPOS 2018, 106) es clave para entender la concepción platónica del coraje. Gran parte de la reflexión que sigue en estas páginas está inspirada en las indicaciones que ofrece Vallejo Campos en el libro citado.

ПНГН / F ON S 4 (2019), 141-151 ISSN 2445-2297 www.uc3m.es/pege

I. Hoyos SÁnchez, El coraje y el gobierno de las pasiones DOI https://doi.org/10.20318/fons.2019.4915
} 
coraje que impartió en la Universidad de Yale durante los años 1950 y 1951 reconoce que él tampoco pretende salir airoso allí donde el mismo Platón fracasó (TILLICH 2018 , 18). Por mi parte, quisiera dejar constancia desde el principio de que el objetivo de esta reflexión no es lograr una definición única y universal acerca del coraje, sino más bien dilucidar los posibles vínculos que existen entre el coraje y su cultivo en el contexto de una política entendida como gobierno de las pasiones en la Antigüedad.

El problema del coraje ha recibido una atención minoritaria en los estudios platónicos, si la comparamos con la que han recibido otros temas clásicos (la teoría de las formas, el mito de la caverna, etc.). Una de las pocas monografías dedicada a la cuestión del coraje en la filosofía platónica, es el estudio -no poco controvertido- de L. Rabieh, Plato and the virtue of courage de $2006^{2}$. En dicho texto la autora mantiene que en el planteamiento platónico el coraje es entendido en su sentido genuino como una virtud y, por tanto, está asociado al conocimiento. El coraje tiene, además, un carácter paradójico, al ser tanto causa como consecuencia del conocimiento (RABIEH 2006, 161). Y esto es así, según señala la autora, tanto en el Laques como en la República, pues según Rabieh no es acertado considerar que el Laques sea un diálogo socrático en el que se plantee un problema que no termina de resolverse; y la República, un diálogo ya platónico que resuelve la cuestión ofreciendo una definición de la valentía. El coraje auténtico tanto en el Laques como en la República es, según Rabieh, propiedad del filósofo que conoce la Idea de Bien, y es, por tanto, una virtud asociada con el conocimiento.

Ahora bien, en el libro III y IV de la República Platón se refiere a otra forma en la que el coraje puede expresarse genuinamente sin ser estrictamente racional. Se trata del coraje referido a una determinada parte del alma, la fogosa o irascible, que no es racional aunque sea permeable a los argumentos de la razón; y también, dado el isomorfismo entre el individuo y el estado, del coraje de una determinada clase social, la de los guardianes, que tampoco se define por el conocimiento del Bien, aunque su función resida en conservar las leyes racionales derivadas de éste. Esta otra forma de coraje, que podemos denominar "político", tiene un estatuto mixto en la medida en que su función es mediar para que las demandas de la razón, o las del filósofogobernante, sean atendidas por nuestros deseos y pasiones. Pues bien, es justamente este papel mediador atribuido al coraje lo que constituye el núcleo singular del platonismo y lo que diferencia su planteamiento del propio de las escuelas helenísticas de la Antigüedad, como el cinismo o el estoicismo. En este sentido, P. Tillich señalaba muy acertadamente en las conferencias ya mencionadas que el coraje para Platón, a medio camino entre el elemento intelectual y el sensible del ser humano, es «el esfuerzo no reflexivo hacia lo que es noble. Y como tal ocupa una posición central en la estructura del alma. Es un puente sobre el abismo entre la razón y el deseo. $\mathrm{O}$ al

\footnotetext{
2 Véanse también las monografías de Schmidt 1992, HobBs 2000 y Rosen-Sluiter 2003. Hay también una variedad de artículos y capítulos que analizan esta temática, como DE ROMILLY 1980 sobre el coraje en Tucídides y en Platón, o CALABI 1998 sobre la relación entre el coraje y la parte fogosa del alma en la República, y otros dedicados al análisis del Laques, como GRISWOLD 1986.
} 
menos podría serlo» (TILlich 2018, 19). Es cierto que, como el propio Tillich reconoce, Platón no empleó dicho puente hasta sus últimas consecuencias por los límites que imponía su planteamiento dualista y jerárquico en el ámbito ontológico, epistemológico y axiológico. Pero hay ciertas indicaciones interesantes en la República que nos permiten reconstruir una imagen de la concepción platónica del coraje mucho más matizada y mediadora de la que ofrecieron, por ejemplo, los cínicos o los estoicos. Ésta es la hipótesis fundamental que trataré de explorar en este estudio.

Para alcanzar este objetivo es muy relevante considerar la reflexión que Platón expone en los libros III y IV de la República sobre la importancia de la educación musical de los guardianes, cuya formación no puede ser reducida a la gimnasia. Apelar a esta pedagogía pro-racional nos pone en la pista de las diferencias entre este largo camino formativo platónico, y el atajo a la virtud que van a proponer otras escuelas helenísticas como la cínica. Sócrates le indica a Glaucón en el libro III de la República que «»la educación musical es de suma importancia a causa de que el ritmo y la armonía son lo que más penetra en el interior del alma y la afecta más vigorosamente» (401d 4-7) . Aquel que ha sido educado musicalmente como se debe -continúa argumentando Sócrates-, y esto es importante, percibirá más agudamente las deficiencias y la falta de belleza, reprobando las cosas feas, antes de ser capaz de alcanzar la razón de las cosas (402a 2). Y cuando sea capaz de alcanzar dicha razón -concluye el sabio- estará mejor dispuesto para ella porque la reconocerá como algo familiar (402a 3-5). La educación musical es crucial porque nos prepara para la razón, produciendo una familiaridad, e incluso una adhesión, a sus contenidos.

Platón no considera aquí la música como lenguaje de las pasiones. La valoración positiva de la educación musical de los guardianes es coherente con la conocida crítica platónica a la poesía trágica de su tiempo y a toda forma de arte que no se ajuste a la belleza de lo racional. Platón contempla aquí la música desde una perspectiva matemática. Tal y como señala en la República, la música tiene que concluir en el amor por lo bello (III 403c 5-6), es decir, en el amor por la belleza de lo racional. La música debe atender a la armonía, al orden expresable numéricamente y, por tanto, a lo racional, de modo que cualquier músico que no siguiese este principio y que se valiese de las pasiones para crear o representar sus creaciones, quedaría inmediatamente expulsado de la ciudad ideal. Todo artista que represente a sus personajes como presas del miedo, o de la vergüenza, sería inmediatamente condenado por Platón. En el libro III de la República, Sócrates señala que Homero no debe representar a Aquiles ni a los dioses lamentándose, en un mar de lágrimas, porque esto haría que el ser humano «ante los más pequeños infortunios, se quejase y se lamentase, sin sentir vergüenza ni tener paciencia» (388d). Es decir, si los artistas nos familiarizan con héroes para los que ni siquiera la vergüenza puede contener sus pasiones, entonces cualquier ciudadano, y cualquier soldado, estará más predispuesto para dejarse llevar

\footnotetext{
${ }^{3}$ Los textos citados de la República de Platón están tomados de la edición y traducción de C. Eggers para la editorial Gredos en la edición de 1988.
} 
por el miedo a la muerte o cualquier otra pasión. No se avergonzará, puesto que tampoco lo hace el héroe, de mostrarse asustado. En este sentido, Platón reconoce que la vergüenza es positiva en la medida en que introduce un principio de moderación en los comportamientos. Evitaría que el soldado se muestre temeroso ante la muerte o ante la desgracia y que, por imitación, este temor calase en el resto de los guardianes que tienen que defender la ciudad. La vergüenza puede dar una apariencia de orden, de equilibrio y de racionalidad. Puede llevar a los guardianes a comportase como si fuesen racionales y, por tanto, como si supiesen que la muerte no es ningún mal para él ni para el resto de los soldados. «Un hombre razonable no juzgará -escribe Platónque, para otro hombre razonable del cual sea compañero, la muerte es terrible», de modo que no temerá ni la muerte propia ni la de su compañero, conservando así la moderación y el dominio de sí (387d). De este modo, los guardianes, no porque tengan conocimiento, sino por vergüenza, actuarán como tipos sub-filosóficos que imitan los modelos de autosuficiencia que la ciudad necesita (cf. RABIEH 2006, 122123). Es cierto que la vergüenza no es el mejor aval para el coraje, pues ya sabemos que el programa educativo que concibe Platón es mucho más complejo y matizado (cf. RABIEH 2006, 123 y sg.). Pero sí parece acertado señalar que la vergüenza desempeña un papel más positivo en el esquema platónico de lo que lo hará en el enfoque cínico.

Sócrates afirma sin ambages que es necesario supervisar y forzar las imágenes del buen carácter en las distintas formas de arte (poesía, pintura, artesanía ...) y de expulsar a aquellos artistas que no cumplan con esta condición, «para evitar que nuestros guardianes crezcan entre imágenes del vicio como entre hierbas malas» (401b 1). En cambio, -arguye- habría que buscar a aquellos artistas que estén capacitados, por sus dotes naturales, para seguir las huellas de la belleza racional. «Así los jóvenes -concluye- como si fuesen habitantes de una región sana, extraerán provecho de todo, allí donde el flujo de obras bellas excita sus ojos o sus oídos como una brisa fresca que trae salud desde lugares salubres, y desde la tierna infancia los conduce insensiblemente hacia la afinidad, la amistad y la armonía con la belleza de lo racional) (III 401c-d).

F. Pelosi en su estudio sobre Plato: on Music, Soul and Body, señala que Platón se adhiere a la teoría del êthos musical, típica de la concepción antigua de la música, cuando le atribuye a ésta el poder de modelar el alma de acuerdo con contenidos éticos. Y esto procede, según Pelosi, no tanto de la especulación filosófica, sino de los mitos y del uso de la música en ritos mágicos y religiosos (PELOSI 2010, 29). No obstante, al margen de la influencia pitagórica a la que apunta Pelosi, lo que me parece más significativo del planteamiento platónico es que le atribuye a la música la capacidad de generar afinidad, amistad y armonía con la belleza de lo racional. Subrayo esta frase de la República porque expresa justamente que la música -como dice PELOSI 2019, 23- nos adhiere afectivamente al orden y lo racional. Y esto es fundamental para el problema de la justicia que hilvana toda la República platónica. 
Sócrates se pregunta cómo podría lograrse que los guardianes tengan un amor tan persistente hacia la ciudad, una convicción tan firme que, en toda circunstancia, a pesar de la violencia que pueda ejercer sobre ellos el sufrimiento y el miedo a la muerte, o la atracción de los placeres, sigan obrando de un modo que convenga a la ciudad. La educación musical que culmina en el amor por la belleza de lo racional es una de las condiciones para que se genere esta convicción firme, que es, precisamente, lo que va a definir a la valentía en el planteamiento platónico. "Allí en la música, señala Sócrates en el libro IV- creo que debemos edificar la resistencia de los guardianes» (424d 1-2). Porque «cuando los niños comienzan debidamente, gracias a la música introducen en sus juegos un afecto por el orden» (425a 3-5). Sócrates ha explicado en el libro III que el hombre que no se relaciona con la Musa, se vuelve enemigo de la razón y no se acostumbra a persuadir por medio de argumentos, sino por la violencia y la fuerza, como una fiera, para conseguir sus propósitos (411e 10). En cambio, la música basada en la armonía, vuelve «la fogosidad, dúctil como el hierro, y de rígida e inservible, se hace útil» (411b 1-3). El afecto por el orden que la música suscita es un elemento clave en la génesis de la verdadera valentía, que se distingue de la brutalidad, y que debe ser la cualidad fundamental de los guardianes de la ciudad ideal justa.

Por otra parte, esta afinidad con los contenidos de la razón que la música suscita, indica, según Pelosi, que el principal elemento implicado en la educación musical es el irascible (thymoeidēs: PELOSI 2010, 23). Es cierto que, en última instancia, en la música van a estar implicadas las tres partes del alma: la concupiscible, en la medida en que la música genera opiniones que resisten las seducciones del placer o la violencia del dolor o del miedo; y la racional, en la medida en que la música será finalmente concebida como ciencia de la armonía en el libro VII de la República (PELOSI 2010, 114). Pero en lo que refiere al papel generador de coraje que la música propicia, el principal elemento implicado es el irascible. Y esto de nuevo nos pone en la pista de la singularidad de la lectura platónica del coraje, con respecto a otros enfoques antiguos como el propio del cinismo o el estoicismo. Esta particularidad remite al estatuto intermedio de la valentía educada musicalmente, pues sin ser estrictamente racional, tiene la capacidad de conservar opiniones que son afines a la razón, poniendo límite a la presión ejercida por pasiones como el miedo o el placer. En las escuelas helenísticas posteriores, en cambio, la valentía no tiene este carácter mixto, sino que es concebida ya como un ejercicio estrictamente racional contra las pasiones.

Ahora bien, Platón considera en el libro III que «después de la música, los jóvenes deben ser educados por medio de la gimnasia» (403c 8-9). Son necesarias ambas para encontrar un equilibrio que huya tanto de la rudeza de aquel que sólo se entrena gimnásticamente, y de la pusilanimidad que una educación exclusivamente musical puede provocar a la larga en el guerrero (410c). Sócrates dice «que algún dios ha concedido a los seres humanos estas dos artes, la música y la gimnasia, con miras a estas dos cosas: la fogosidad y el ansia de saber» (411e). En relación con el planteamiento cínico, hay una diferencia notable y es que su itinerario para cultivar 
el coraje no se basa en la educación musical, sino en la gimnasia, que además está referida al alma y al cuerpo en la misma medida y sin privilegio de uno sobre otro. Sin embargo, la gimnasia para Platón lo es principalmente del alma, aunque tenga sus efectos positivos sobre el cuerpo. Sócrates aclara a su interlocutor que es equivocado pensar que la gimnasia cuida del cuerpo y la música del alma. Ambas son artes para el cuidado del alma (410c 1-5), puesto que la excelencia del alma puede hacer que el cuerpo sea lo mejor posible, pero no sucede a la inversa (403d). En la siguiente sección retomaremos esta idea. Antes de ello, hay que señalar cuál es la conclusión que Sócrates va a alcanzar a lo largo de esta larga digresión acerca del coraje.

En el libro IV, Platón recuerda que un estado es valiente porque una de sus partes lo es, es decir, gracias al coraje de los guardianes se conservan, en toda circunstancia, las opiniones conformes a lo que el legislador ha dispuesto en la ciudad. Sócrates insiste en el término "conservación" para hacer ver que la valentía es justamente un modo de conservación, en concreto, «la conservación de la opinión engendrara por la ley, por medio de la educación, acerca de cuáles y cómo son las cosas temibles. Y he dicho -señala Sócrates- que ella era conservación en toda circunstancia en el sentido de que quien es valiente ha de mantenerla -y no expulsarla del alma nunca- tanto en los placeres y deseos como en los temores. Y estoy dispuesto a representar lo que pienso por medio de una comparación, si quieres» (429b-d). La metáfora que usa Platón es crucial para comprender los detalles de su concepción de la valentía. Sócrates nos cuenta cómo los tintoreros cuando quieren teñir un tejido, seleccionan en un primer paso las lanas blancas, que no tienen mezcla, de entre aquellas que son de diversos colores; y, en segundo lugar, tratan cuidadosamente la lana para que adquiera un tono púrpura, y sólo entonces la sumergen en tinte. Si no se realiza este procedimiento, rápidamente se destiñe la lana pintada al aplicar jabón o algún otro disolvente (430 $\mathrm{a}-\mathrm{c})$

Suponte entonces -continúa Sócrates- que algo semejante hacemos en lo posible también nosotros, cuando hemos seleccionado a los militares y los hemos educado por medio de la música y la gimnasia. Piensa que no tenemos otro propósito que el de que adquieran lo mejor posible, al seguir nuestras leyes, una especie de tintura que sea para ellos -gracias a haber recibido la naturaleza y crianza apropiadas- una opinión indeleble acerca de lo que hay que temer y de las demás cosas; de manera tal que esa tintura resista a aquellas lejías que podían borrarla: por ejemplo, el placer, que es más poderoso para lograrlo que cualquier soda calestrana; o bien, el dolor, el miedo y el deseo, que pueden más que cualquier otro jabón. Pues bien, al poder de conservación -en toda circunstancia- de la opinión correcta y legítima lo considero valentía, y así lo denomino, si no lo objetas.

Según Platón, cualquier opinión que no proceda de haber recibido la educación descrita, o de acuerdo con la metáfora socrática, que no haya sido tintada del modo adecuado, incluso aunque fuese correcta, no se consideraría una opinión legítima, ni se describiría como valiente la capacidad de conservarla. Por tanto, la valentía es 
definida por Platón como la capacidad de conservar en cualquier circunstancia y frente a la fuerza ejercida por el placer, el dolor o el temor irracionales, una opinión educada acerca de lo que hay que temer, según ha dispuesto la ley. Es, por tanto, una "tintura indeleble", una convicción o actitud constante que resiste cualquier disolvente (VALLEJO CAMPOS 2018, 106) gracias al tratamiento que ha recibido.

Pero hay un segundo aspecto de la valentía o el coraje que Platón subraya al establecer esta comparación. Como bien ha precisado Vallejo, aunque reconozcamos que hay un elemento cognitivo en el coraje en la medida en que éste conserva una opinión educada, dicho elemento cognitivo no es estrictamente racional. La valentía se fundamenta en una opinión y no en un saber (VALLEJO CAMPOS 2018, 106) ${ }^{4}$. Y ello porque, además de alojarse en la parte irascible del alma, la metáfora del teñido señala que el coraje viene dado por un procedimiento externo, el tinte que se aplica desde fuera, y no por la reflexión propia que propicia la mayéutica socrática, lo cual descarta el carácter estrictamente racional de esta virtud (VALLEJO CAMPOS 2018, 106). De momento, en el libro IV, Sócrates dice estar satisfecho con lo concluido sobre la valentía, y tras recordar, que es una virtud referida a todo el estado, porque es propiedad de una clase determinada del mismo, la de los guardianes (429b), se dispone a reflexionar sobre la justicia. Como argüiré a continuación, esta consideración del coraje como función de una clase determinada, gracias a la cual se puede decir que un estado es valiente, es otro de los aspectos en los que el platonismo y el cinismo se distancian.

\section{Coraje e impasibilidad en las escuelas helenísticas: Ios cínicos}

En la versión de Diógenes Laercio encontramos varias anécdotas acerca de la rivalidad entre Diógenes el cínico y Platón que muestran la distancia que hay entre ambos tipos de filosofía; una, la cínica, más práctica y naturalista; la platónica, más teórica e idealista. Famosa es la refutación que el cínico realiza de la definición platónica de hombre como animal bípedo implume, mostrando un gallo desplumado en la escuela (D.L. VI 40), o la irónica invitación que Diógenes le hace a Platón para que participase de los higos secos que comía aquél, reprochándole al intentar éste comerlos: «Participar dije, no zampártelos!» (D.L. VI 25) ${ }^{5}$. Este tópico, sin embargo, puede resultar enriquecido con la visión que del coraje tenían los cínicos antiguos. Y es que, a diferencia de lo que en principio puede parecer, el coraje cínico, como también el estoico, no actúa como puente entre la razón y las pasiones, sino que se sitúa claramente del lado de la primera en contra de las últimas. En el retrato de los cínicos antiguos que nos transmite Diógenes Laercio, en el que voy a centrar mi reflexión, el coraje cínico tiene un carácter racional y está asociado a la autosuficiencia y la impasibilidad, como es propio de las escuelas helenísticas.

${ }^{4}$ A. Vallejo Campos se refiere en este contexto a la reflexión de Calabi 1998 (cf. VALLEjo Campos 2018, 106).

5 Los textos citados de las Vidas de los filósofos ilustres de Diógenes Laercio (D.L.) corresponden a la traducción de C. García Gual para Alianza Editorial, 2007. 
Diógenes Laercio nos recuerda la afiliación socrática del fundador del cinismo, Antístenes, y cómo tomó de Sócrates precisamente la firmeza de carácter, emulando su impasibilidad (D.L. VI 11). «Antístenes abrió camino, además, a la impasibilidad de Diógenes, la continencia de Crates y a la firmeza de ánimo de Zenón, y él puso los fundamentos básicos de su régimen político» (D.L. VI 15). El coraje se opone completamente, desde la perspectiva cínica, al azar, al igual que la naturaleza se opone a la ley o convención, y el razonamiento a la pasión. Coraje, naturaleza y razón van de la mano para el cínico, y a ellos se opone el azar, la convención y las pasiones que el cínico combate (D.L. VI 38). Las pasiones esclavizan a aquél que no se ha endurecido lo suficiente, de modo que según Diógenes, los débiles son siervos de sus pasiones, al igual que los criados lo son de sus amos (D.L. VI 66). Es cierto que una lectura más completa de los distintos testimonios que conservamos sobre los cínicos nos daría un retrato más exhaustivo de la cuestión 6 . Sin embargo, realizar una lectura pormenorizada de este tema excede los límites de este trabajo, cuyo objetivo es señalar algunas de las diferencias que hay entre la concepción platónica y cínica del coraje y de su cultivo en un contexto político. En ambos casos, la política es entendida, en cierta medida, como un gobierno racional de las pasiones. Pero el enfoque desde el que se piensa esta cuestión es muy distinto.

En primer lugar, en el esquema platónico la política remite al estado gobernado racionalmente por el filósofo. De dicho estado podemos decir que es valiente si la clase a la que le corresponde la valentía, es decir, la de los guardianes, lo es. La valentía del estado no depende de que el resto de sus ciudadanos sean valientes (cf. VALLEJO CAMPOS 2018, 105). Al mantener esta tesis el enfoque platónico es muy excepcional. Platón no piensa que, independientemente de la clase a la que se pertenezca, cualquiera puede devenir valiente si recibe la formación necesaria. Hay que seleccionar de entre las mejores lanas, las más puras, según la metáfora empleada por Sócrates. Cualquiera no puede ser educado para ser valiente; ni cualquiera, ni en cualquier momento de su vida. La juventud, como observa M. Foucault en los cursos que impartió en el Collège de France en 1982, es el momento más propicio para ser educados en la república platónica (FOUCAULT 2005, 128 y sg.) ${ }^{7}$. En cambio, en el enfoque cínico, el coraje, vinculado a la sinceridad o al modo de vivir en la verdad, es eminentemente individual, y cualquiera que se entrene en el modo de vida cínico, independientemente de su nobleza de cuna, de si pertenece a la clase de los guardianes o no, puede llegar a ser valiente. Además, aunque el coraje cínico tiene también una dimensión política entendida como gobierno de las pasiones, el cínico altera el campo de juego de lo político. Para el cínico la política se juega en un espacio público mucho

\footnotetext{
${ }^{6}$ Para un análisis de la lectura del último Foucault sobre los cínicos, y un tratamiento algo más pormenorizado de la relación entre coraje y pasión en los cínicos antiguos, véase HoYOs SÁNCHEZ 2018, $1-8$.

${ }^{7}$ M. Foucault ha dilucidado esta idea en el contexto de las diferencias entre el cuidado de sí en el platonismo y las prácticas de sí en los siglos I y II. Véase, por ejemplo, la clase del 27 de enero de 1982 transcrita en FOUCAULT 2005, 128 y sg.
} 
más abierto que el concebido por Platón ${ }^{8}$. El gobierno no lo ejerce el estado gobernado por el filósofo, ni hay clases con virtudes específicas. El coraje del cínico es político en la medida en que tiene como referente siempre al otro, al que interpela incómodamente en todo momento, instándole a cuestionar su modo de vida convencional. De este modo, es justamente viviendo, mostrando en la propia vida valentía, como hace política el cínico, como gobierna sus pasiones y también las pasiones de la humanidad en su conjunto (FOUCAULT 2010).

Además, el entrenamiento que propone el cínico para ser valientes es un trabajo individual que cualquiera puede realizar sobre su propia vida. La nobleza no viene dada por la cuna, sino por la virtud (D.L. VI 11). Cualquiera podría volverse valiente si se entrenase en el modo de vida cínico; y además, esto podría hacerlo a lo largo de toda una vida, y especialmente en la vejez (FOUCAUlT 2005, 128 y sg.). Cuando le decían a Diógenes de Sinope que era viejo y que descansara ya, él respondía: «si corriera la carrera de fondo, ¿debería descansar al acercarme al final o más bien apretar más?» (D.L. VI 34).

Por otra parte, en este entrenamiento cínico no juega un papel importante ni la educación musical ni la pedagogía del amor por la belleza de la que habla Platón. El cínico propone un atajo hacia la virtud, un camino directo desde la gimnasia (física y espiritual) a la valentía9. Antístenes afirmaba «que la virtud es suficiente en sí misma para la felicidad, sin necesidad de nada a no ser la fortaleza socrática. Que la virtud está en los hechos y no requiere ni muy numerosas palabras ni conocimientos» (D.L. VI 11). Y en una muy probable afirmación antiplatónica, Diógenes el cínico señalaba la contradicción que había en los músicos que afinaban las cuerdas de la lira y tenían desafinados los impulsos del alma (D.L. VI 27). Diógenes Laercio nos cuenta al final de su relato sobre Diógenes que «de la música, la geometría, la astrología y las ciencias de esa especie se desentendió, por considerarlas inútiles e innecesarias» (D.L. VI 73). Mónimo de Siracusa (s. IV a.G.), discípulo de Diógenes, del que Menandro, en su pieza teatral El palafrenero, dice que estaba por encima del "conócete a ti mismo", fue riguroso en su desprecio de la opinión pública y en el hábito de proseguir la verdad (D.L. VI 83). Todos estos testimonios sobre los cínicos muestran que el coraje, desde su óptica, no requiere ni educación musical ni conocimientos teóricos abstractos.

No obstante, esto no quiere decir que el coraje cínico sea irracional. Los cínicos defienden que «en la vida hay que tener dispuesta la razón o el lazo de horca» (D.L. VI 24). El modo de vida cínico, en el que se muestra el coraje, es racional y natural. La razón, que está en sintonía con la naturaleza, nos equipa contra el azar. El coraje, que es racional, también lo hace. Por otra parte, según nos cuenta Diógenes Laercio,

\footnotetext{
8 Para un análisis más detallado de las características de la política cínica, véase Husson 2011.

9 «[Diógenes de Sinope] aportaba pruebas de que fácilmente se desembocaba de la gimnasia en la virtud. Pues en los oficios manuales y en los otros se ve que los artesanos adquieren una habilidad manual extraordinaria a partir de la práctica constante, e igual los flautistas y los atletas cuánto progresan unos y otros por el continuo esfuerzo en su profesión particular; de modo que si éstos, trasladaran su entrenamiento al terreno espiritual, no se afanarían de modo incompleto y superfluo» (D.L. VII 70).
} 
para Antístenes la virtud es enseñable, de modo que podríamos decir que la fortaleza o el coraje también tendrían que serlo. En cualquier caso, lo que parece más claro es que el cultivo del coraje en el cinismo no es equiparable a la pedagogía platónica basada en la música y en la gimnasia del alma. El cínico aplica una medicina correctora (FOUCAULT 2005, 127) que consiste en endurecerse corporal y mentalmente $^{10}$, entrenarse en el desprecio del placer (D.L. VI 71) y sobre todo en practicar la impopularidad y la anaideia o el impudor frente a las convenciones (D.L. VI 11 y 69). La superación de la vergüenza, que es una pasión eminentemente social que nos liga a lo convencional, es el elemento más distintivo de la concepción cínica del coraje y lo que en mayor medida la distancia de la noción platónica.

Diógenes de Sinope «troquelaba con un nuevo cuño lo convencional de un modo auténtico, sin hacer ninguna concesión a las convenciones de la ley, sino sólo a los preceptos de la naturaleza, afirmando que mantenía el mismo género de vida que Heracles, sin preferir nada a la libertad» (D.L. VII 71). Antístenes consideraba que la impopularidad es un bien (D.L. VI 11). Y las anécdotas sobre el comportamiento impudoroso del cínico son todo un clásico en la recepción del cinismo. Sin embargo, Platón concede a la vergüenza un valor positivo, aunque sea sólo instrumental, tal y como hemos visto a propósito del análisis del libro III de la República, y la obligación que, según Sócrates, tienen los artistas, incluido Homero, de representar a los héroes y a los dioses sin temores, aunque en principio sea por vergüenza (388d). La vergüenza recibe una valoración más positiva en el planteamiento de Platón que en el cínico, aunque Platón tampoco la equipare al conocimiento racional.

En definitiva, el impudor es el elemento más exclusivo del coraje cínico. No encontramos un desprecio de la vergüenza tan claro ni en el planteamiento platónico, ni en el de otras corrientes helenísticas como el estoicismo, con el que, por otra parte, el cinismo es afín en otros aspectos. De hecho, la vergüenza para el estoico puede ser considerada un temor no razonable, una pasión; pero también puede ser concebida como reverencia, es decir, como una traducción razonable de la cautela, es decir, una eupatheia. El estoico es más afín al planteamiento platónico en este punto. Pero a diferencia de Platón, y al igual que piensan los cínicos, ellos conciben la valentía como un conocimiento, un conocimiento de lo que hay que elegir y lo que hay que temer y lo ambiguo (D.L. VII 92), y no meramente como una opinión indeleble que conserva las leyes de la razón. El coraje en las escuelas helenísticas está del lado de la razón y en contra de las pasiones sin mediación ni puente. En ese sentido, y a modo de balance, considero que una de las especificidades del enfoque platónico sobre el coraje y su cultivo en un contexto político tiene que ver con el estatuto mixto de la valentía platónica, casi racional, sin serlo estrictamente, y capaz de mediar para que las demandas de la razón lleguen a nuestros deseos y pasiones, manteniendo el equilibrio de toda el alma o de todo el estado platónico. Lejos de lo que puede parecer en Platón

${ }^{10}$ Para un estudio detallado de las características de la ascesis cínica, véase GoULET-CAZÉ 1986. 
encontramos un tratamiento de la valentía lleno de matices que huye de la ortodoxia y de la cerrazón con los que a veces se ha vinculado al filósofo de Atenas.

\section{Bibliografía}

Calabi, F. (1998), «Thymoeides/Andreia», en Vegetti, M. (ed.), La Repubblica di Platone. Traduzione e commento, Napoli, III, 187-203.

de Romilly, J. (1980), «Réflexions sur le courage chez Thucydide et chez Platon», Revue des Études Grecques XCIII 2, 307-323.

Diógenes Laercio (2007), Vidas de los filósofos ilustres, Trad. C. García Gual, Madrid.

Foucault, M. (2005), La hermenéutica del sujeto, Curso del Collège de France 1982, Ed. F. Ewald y A. Fontana bajo la dirección de F. Gros, Trad. H. Pons, Madrid.

Foucault, M. (2010), El coraje de la verdad. El gobierno de sí y de los otros II. Cursos del Collège de France 1983-1984, Ed. F. Ewald y A. Fontana bajo la dirección de F. Gros, Trad. H. Pons, México.

Goulet-Cazé, M.O. (1986), L’ascèse cynique. Un commentaire de Diogène Laërce VI 70-71, Paris.

Griswold, Ch. (1986), «Philosophy, Education and Courage in Plato’s Laches», Interpretation $14,177-193$.

Hobbs, A. (2000), Plato and the Hero: Courage, Manliness, and the Impersonal Good, Cambridge.

Hoyos Sánchez, I. (2018, «Courage and Passion: the Reading of the Later Foucault of the Cynics», CLCWEB Comparative Literature and Culture 20, 4,1-8 (disponible online https://doi.org/10.7771/1481-4374.3355).

Husson, S. (2011), La République de Diogène. Une cité en quête de la nature, Paris.

Pelosi, F. (2010), Plato: on Music, Soul and Body, Trad. S. Henderson, Cambridge.

Platón (1988), República, Trad. C. Eggers Lan, Madrid.

Rabieh, L.R. (2006), Plato and the virtue of courage, Baltimore.

Rosen, R.M. - Sluiter, I. (eds.) (2003), Andreia: Studies in Manliness and Courage in Classical Antiquity, Leiden.

Schmidt, W. (1992), On Manly Courage: A Study of Plato's Laches, Southern Illinois UP. Tillich, P. (2018), El coraje de ser, Madrid (19521).

Vallejo Campos, A. (2018), Adonde nos lleve el logos. Para leer la República de Platón, Madrid. 